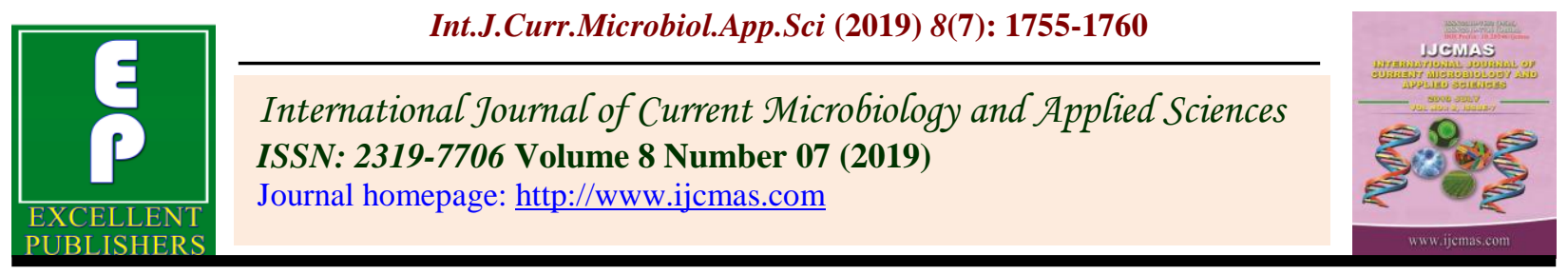

Original Research Article

https://doi.org/10.20546/ijcmas.2019.807.208

\title{
Evaluation of Microbial Antagonists against Sarocladium oryzae Causing Sheath Rot Disease of Rice (Oryzae sativa L.)
}

\author{
B. Bora* and M.S. Ali \\ Department of Plant Pathology, Assam Agricultural University, Jorhat-785013, Assam, India \\ *Corresponding author
}

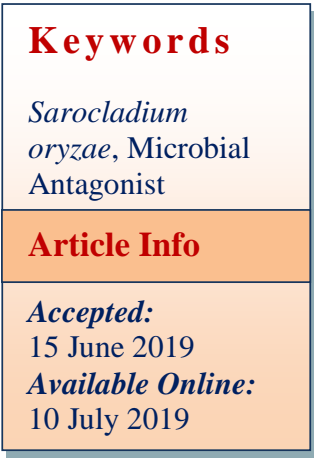

A B S T R A C T

Sheath rot disease of rice is an emerging disease of rice inflicting severe yield losses. Chemical pesticides are exclusively used for the management of the disease and application of these chemicals over a long period may result in development of resistance, concerns about pesticide residue risk, health and environmental pollution and health hazards which demands for a sustainable means of disease management. The present investigation was carried out to evaluate the efficacy of few microbial antagonist viz. Trichoderma harzianum, T. asperellum, T. viride, T. pseudokoningii, T. parareesei, Pseudomonas fluorescens, Bacillus megaterium and Bacillus subtilis against Sarocladium oryzae in vitro. All the microbial antagonists were found to be effective in inhibiting the radial growth of $S$. oryzae. Out of all the tested antagonists, Pseudomonas fluorescence showed highest $(82.06 \%)$ inhibition of the mycelial growth of the pathogen. Among the fungal antagonists, $T$. harzianum was found to be most effective with 65.21 $\%$ inhibition over the other species.

\section{Introduction}

Rice (Oryza sativa L.) is the staple food of nearly half of the world's population and mainly grown and consumed in Asian counties such as China, India, Indonesia, Japan, Thailand, Pakistan, Bangladesh, North and South Koreas, Myanmar, Philippines, Sri Lanka etc. The productivity of rice is threatened by a number of fungal and bacterial diseases attacking the crop and causing enormous yield loss. Among the various diseases of rice, sheath rot caused by Sarocladium oryzae (Sawada) Gams. and Hawksworth has gained the status of a major disease of rice and reduce the yield considerably all over the rice growing areas of the world. The disease causes empty grain production (Kulwant and Mathur, 1992) and glume discolouration (Sachan and Agarwal, 1995). It also causes poor grain filling and reduction in seed germination (Vidyasekaran 
et al., 1984). Seeds from infected panicles became discoloured and sterile (Mew and Gonzales, 2002). The stem borer or mite damage to the boot or leaf sheaths increase the severity of this disease.

Chemical pesticides are exclusively used for the management of the disease but not considered as a long term solution because it may cause health and environment hazards, residue persistence and elimination of natural enemies and development of resistance. Therefore, the need for an alternative means of control of sheath rot disease has become imperative. The use of microorganisms as biological control agents to control plant disease has emerged as powerful alternative method (Kulkarni et al., 2007). The rich diversity, complexity of interactions and numerous metabolic pathways makes microbe an amazing resource for biological activity (Emmert and Handelsman, 1999; Alabouvette et al., 2006 and Raghukumar, 2008).

Microorganisms have been described, characterized, and tested for their use as biocontrol agents against diseases caused by soil borne pathogens since last few decades. Antagonistic fungi have been used exclusively as biocontrol agents to control plant diseases with $90 \%$ of applications being made using different strains of Trichoderma viz. T. harzianum, T. virens, T. viride (Benitez et al., 2004).

Several bacterial species namely Pseudomonas and bacillus spp were widely used as biocontrol agents against various plant pathogens. Pseudomonas fluorescence also plays an important role as biocontrol agent in management of several soil borne pathogens (Sakthivel and Gnanamanickam, 1987). Therefore, the present experiment was undertaken to evaluate the best effective microbial antagonist against the sheath rot pathogen.

\section{Materials and Methods}

\section{Collection of diseased specimens}

Rice (Oryzae sativa) plants showing typical symptoms of sheath rot disease were selected for collection of disease specimen. The boot leaf sheath showing the typical symptoms of sheath rot disease were collected from the experimental farm, Regional Agricultural Research Station, North Lakhimpur. The samples were brought to the laboratory for critical observation and investigations for further studies.

\section{Isolation and purification of the causal organism}

The diseased specimens (infected boot leaf sheath) showing typical symptom were first washed thoroughly with tap water and then rinsed with distilled water for further studies. Small portion of infected parts containing healthy as well as diseased tissues were cut in to $0.5 \mathrm{~cm}$ pieces with the help of sterilized scalpel blade. These pieces were then surface sterilized with 1 percent sodium hypochlorite solution for 2 minutes and rinsed aseptically in three changes of sterilized distilled water to remove traces of the chemical and dried in sterilized blotting paper. The surface sterilized pieces were then transferred aseptically to petri dishes containing 2 per cent sterilized Potato Dextrose Agar (PDA) with the help of a sterilized needle and incubated at $28 \pm 2{ }^{\circ} \mathrm{C}$ for 7-8 days in BOD. The petri dishes were examined at regular time intervals for fungal growth and then transferred aseptically to potato dextrose agar slants.

The fungal culture was purified by single spore isolation method and the fungus isolated during the present study was identified based on the characteristics of the colony characters, mycelium character, conidiophores, and conidia. 


\section{Pathogenicity test}

Susceptible rice variety Mahsuri were grown in the greenhouse to test the pathogenicity of the pathogen. At booting stage, tillers were inoculated with S.oryzae following standard grain inoculum technique (Sakthivel and gnanamanickam, 1987). A total of 25 tillers were inoculated with the isolate of S.oryzae. Observations were made regularly for the appearance and development of symptoms. After 14 days of inoculation, symptoms of sheath rot disease occur.

\section{In vitro antagonism of microbial antagonists}

Microbial antagonist viz Trichoderma harzianum, Trichoderma asperellum, Trichoderma viride, Trichoderma pseudokoningii, Trichoderma parareesei, Pseudomonas fluorescens, Bacillus megaterium and Bacillus subtilis were obtained from department of Plant Pathology, Assam Agriultural University, Jorhat and evaluated for their antagonistic ability against the test fungus, employed by dual culture method (Dennis and Webster, 1971) under in vitro condition. Sterilized PDA medium, melted and cooled at $45^{\circ} \mathrm{C}$, was poured aseptically into sterilized Petri dishes at the rate of $20 \mathrm{ml}$ per plate and allowed to solidify. Mycelial disc of $5 \mathrm{~mm}$ diameter from the edge of actively growing 10 days old culture of $S$. oryzae was separately cut with the help of a sterilized cork borer and was simultaneously placed on the periphery about $1 \mathrm{~cm}$ from the edge of the Petri dishes ( $9 \mathrm{~cm}$ diameter) on one side and kept upto $36 \mathrm{hr}$ for incubation at $28 \pm$ $2{ }^{\circ} \mathrm{C}$ tem. Similarly mycelial disc of $5 \mathrm{~mm}$ diameter from the edge of actively growing fungal antagonists were placed on periphery about $1 \mathrm{~cm}$ from the edge of the Petri dishes on the opposite sides. In case of bacterial antagonist, the plates were again cross streaked with microbial antagonists
(Nandakumar et al., 2001). Four replications were maintained for each treatment. The Petri dishes containing PDA medium inoculated with the S. oryzae alone served as control. All the Petri dishes were incubated at $28 \pm 2{ }^{\circ} \mathrm{C}$ temperature and observation for inhibition of the test fungus were recorded from $3^{\text {rd }}$ day onward up to 15 days.

The radial mycelia growth of the test fungus for the each treatment was measured and compared with radial growth of the (untreated) control. The percent inhibition of S. oryzae was calculated for each treatment by adopting the following formula.

Inhibition $(\%)=\mathrm{C}-\mathrm{T} / \mathrm{C} \times 100$

Where,

$\mathrm{C}=$ Diameter of fungus colony $(\mathrm{cm})$ in control plate

$\mathrm{T}=$ Diameter of fungus colony $(\mathrm{cm})$ in treated plate

\section{Results and Discussion}

\section{Pathogenicity test}

Inoculated tillers were observed after 14 days of inoculation for development of sheath rot symptoms. Sheath rot infected panicles were harvested at maturity. To confirm the infection by S.oryzae, seeds were placed onto PDA plates and incubated at $28 \pm 2{ }^{\circ} \mathrm{C}$ tem An abundant whitish powdery growth were also observed.

\section{Effect of microbial antagonists on mycelia growth of Sarocladium oryzae}

The results revealed (Table 1 and Fig. 1) that all the microbial antagonists significantly inhibited the mycelia growth of Sarocladium oryzae. Among all the antagonist, 
Pseudomonas fluorescence was found most effective showing $82.06 \%$ inhibition of the mycelial growth of S.oryzae while Trichoderma parareesei exhibited least inhibition $(39.78 \%)$ of the mycelial growth of the pathogen. The results of the present study are in conformity with the findings of the earlier workers who reported the inhibitory effect of Trichoderma spp on S. oryzae.

In their work on antagonism of soil fungus and $T$. viride against $S$. oryzae. Paneerselvam and Saravanamuthu (1996) reported the maximum inhibition of $S$. oryzae with $T$. viride. Gopalakrishnan and Valluvaparidasan (2006) reported that different isolates of $T$. viride, $P$. fluorescens and Bacillus subtilis showed inhibitory effect on $S$. oryzae ranging from 10.90 to 82.18 per cent. Reduction in the intensity of rice sheath rot disease in field by use of $T$. viride, $T$. harzianum, B. subtilis and $P$. fluorescens was reported by Chaliganjewar et al., (2010b). Varati (2012) reported that among the different species of Trichoderma used, T. harzianum was found to be the most inhibitory to the growth of $S$. oryzae with 76.25 per cent inhibition followed by $T$. reesei with 75 per cent inhibition and $T$. viride with 74.68 per cent inhibition. T. longibrachiatum and $T$. aureoviride caused 73.75 and 73.43 per cent inhibition, respectively.

Similar findings are also reported by Selvaraj et al., (2011) that in solid medium under in vitro screening by using dual culture technique, the antagonistic potential of seven Trichoderma species i.e. Trichoderma viride, Trichoderma lignorum, T.album, T.hamatum, T.harzianum, T.glaucum and T.koeningi were assesed, the Trichoderma harzianum was the most antagonistic species under the study.

The inhibition of mycelial growth of Sarocladium oryzae by the antagonistic bacteria is carried out by the production of siderophores like Pseudobactin, pyochelin, pyoveradine, Ferribactin, Ferrichrome, Phytosiderphores, etc., antibiotics like phenazines, pyoluteorin, tropolone, pyocyanine, 2,4-diacyetyl phologlucinol (DAPG), pyrrolntrin, secondary metabolites like Hydrogen cyanide, phenazine-1carboxylic acid (PCA), Oomycin A, chitinase, $\beta-1,3$ glucanase, laminariase etc.

Table.1 Effect of microbial antagonists on mycelia growth of Sarocladium oryzae

\begin{tabular}{|l|c|c|}
\hline \multicolumn{1}{|c|}{ Treatments } & $\begin{array}{c}\text { Mycelial growth } \\
\text { (mm) }\end{array}$ & $\begin{array}{c}\text { \% inhibition of mycelia growth } \\
\text { over control }\end{array}$ \\
\hline T1=Trichoderma harzianum & 20.44 & 65.21 \\
\hline T2=Trichoderma asperellum & 28.15 & 52.09 \\
\hline T3=Trichoderma viride & 24.82 & 57.76 \\
\hline T4=Trichoderma & 32.76 & 44.24 \\
pseudokoningii & & 39.78 \\
\hline T5=Trichoderma parareesei & 35.38 & 82.06 \\
\hline T6=Pseudomonas fluorescens & 10.54 & 67.38 \\
\hline T7=Bacillus megaterium & 19.17 & 71.35 \\
\hline T8=Bacillus subtilis & 16.83 & \\
\hline T9=Control & 58.74 & \\
\hline SEd \pm & 0.46 & \\
\hline CD (P=0.05) & 0.94 & \\
\hline
\end{tabular}




\section{Pathogenicity test}
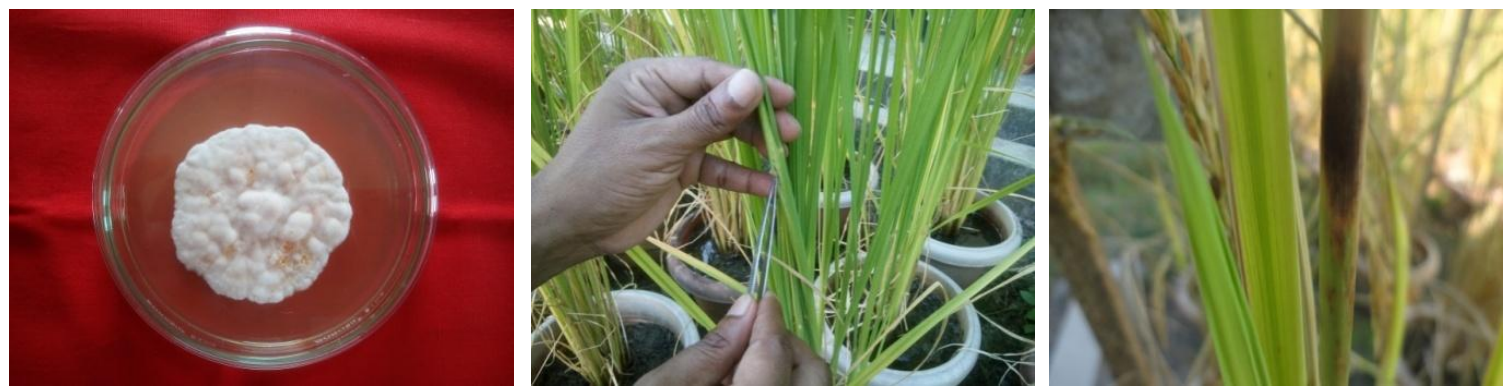

Fig.1 Effect of microbial antagonists on radial growth of Sarocladium oryzae in vitro

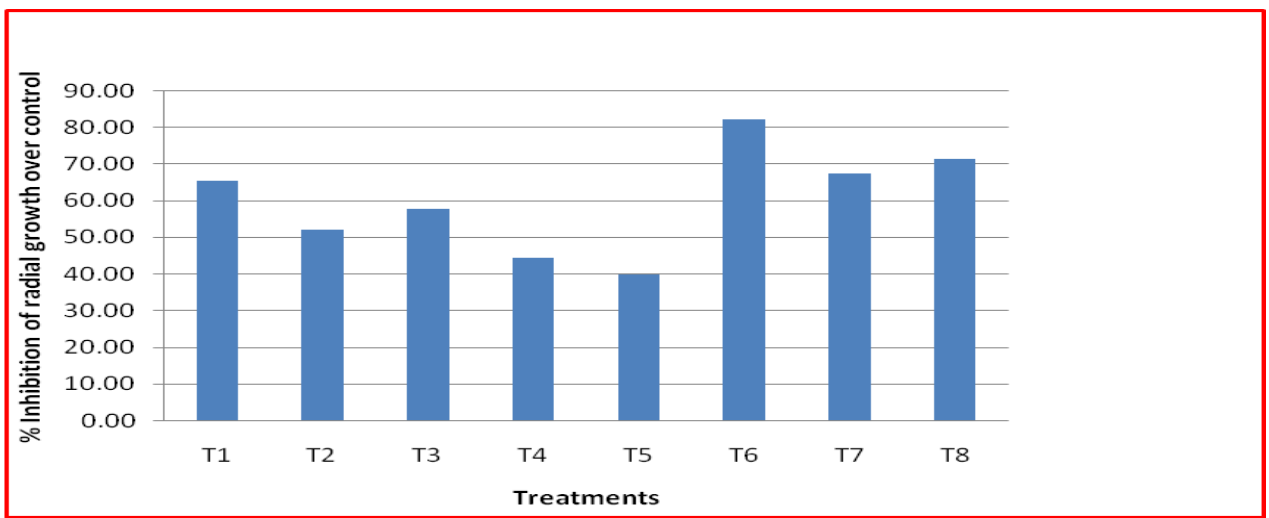

It may be assumed from the above results that the antagonism of Trichoderma spp against $S$. oryzae may be attributed either due to production of antibiotics (Gliotoxin), various enzymes such as exo and endoglucanes, cellobiase, chitinase, laminariae etc, or volatile metabolites or mycoparasitism or competition.

Sheath rot disease of rice caused by Sarocladium oryzae can be managed without much yield loss through effective use of biocontrol agents which will eventually reduce the use of chemical pesticides protecting the environment and health and increase the rice production and productivity through sustainable resource management.

\section{Acknowledgements}

The authors are thankful to Head of Department of Plant Pathology, Dean,
College of Agriculture and Director of Post Graduate Studies, Assam Agricultural University, Jorhat for providing all the necessary facilities.

\section{References}

Alabouvette, C., Olivain, C and Steinberg, C. (2006). Biological control of plant diseases: the European situation. European Journal of Plant Pathology, 114: 329-341.

Benítez, T., Rincón, M.A., Limón, M.C. and Codón, C.A. (2004). Biocontrol mechanisms of Trichoderma strains. International microbiology, 7: 249-260.

Chaliganjewar. S. D., Lakpale. N., Khare. N and Trimurthy, V. S. (2010b). Evaluation of resistance inducing agents against sheath rot disease and yield of rice. Annals of Plant protection sciences. 18(1): 273-274. 
Dennis, C. and Webster, J. (1971). Antagonistic properties of speciesgroups of Trichoderma II. Production of volatile antibiotics. Trans. Br. Mycol. Soc., 57(I):41-48

Emmert, E.A.B and Handelsman, J. (1999). Biocontrol of plant disease. a (Gram-) positive perspective. Microbiology Letters.171: 1-9.

Gopalakrishnan, C. and Valluvaparidasan, V. (2006). Seed-borne biocontrol agents for the management of rice sheath rot caused by Sarocladium oryzae (Sawada) W. Gams \& D. Hawksw. Journal of Biological Control. 20(2):197-204.

Kulkarni, M., Chaudhari, R. and Chaudhari, A. (2007). Novel tensio-active microbial compounds for biocontrol applicatins. In: General Concepts in Integrated Pest and Disease Management (eds. A. Ciancio and K.G. Mukerji). Springer, 295-304.

Kulwanth, S. and Mathur, S.B. (1992). Further evidence of transmission of Sarocladium oryzae through rice seeds and its quarantine significance. Indian Phytopathology. 45(1):454 456.

Mew T.W. and Gonzales. (2002). A Handbook of Rice Seed Borne Fungi. IRRI Science Publishers, 83 pp.

Nandakumar, N., Babu, R., Viswanathan, S., Raguchader, R. and Samiyappan, R. (2001). Induction of systemic resistance in rice against sheath blight disease by Pseudomonas fluorescens. Soil Biol. Biochem. 33(4-5): 603-612.
Paneerselvam, A and Saravanamuthu, R. (1996). Antagonistic interaction of soil fungi against Sarocladium oryzae. Indian journal of Agricultural Research. 30(1): 59-64.

Raghukumar, C. (2008). Marine fungal biotechnology: an ecological perspective. Fungal Diversity, 31: 1935.

Sachan, I.P. and Agrawal, V.K. (1995). Seed discoloration of rice: location of inoculum and influence on nutritional value. Indian Phytopath. 48(1): 14-20.

Sakthivel, N. and Gnanamanickm, S.S. (1987). Evaluation of P. fluorescens for suppression of sheath rot disease and for enhancement of grain yields in rice (Oryza sativa L.). Appl. Environ. Microbiol. 53(9):056-2059.

Selvaraj, Kalaiselvi, S. and Panneerselvam A. (2011). In vitro assessment of antagonistic activity of Trichoderma $s p$. Against Sarocladium oryzae causing sheath rot disease in paddy. Inter. J. of Bio. and Pharmaceutical Techn. 4(1) ISSN 0976-4550.

Varati, U. (2012). Studies on sheath rot disease of rice caused by Sarocladium oryzae (sawada) gams and hawksworth. M.Sc. (Agri.) thesis, Acharya N.G. Ranga Agricultural University Rajendranagar, Hyderabad.

Vidhyasekaran, P., Ranganathan, K. and Rajamanickam, J. (1984). Quality of rice grains from sheath rot affected plants. IRRN. 12(1): 17.

\section{How to cite this article:}

Bora, B. and Ali, M.S. 2019. Evaluation of Microbial Antagonists against Sarocladium oryzae Causing Sheath Rot Disease of Rice (Oryzae sativa L.). Int.J.Curr.Microbiol.App.Sci. 8(07): 1755-1760. doi: https://doi.org/10.20546/ijcmas.2019.807.208 